\title{
Precision Retained Tooth Supported Overdenture - A Viable Treatment Option against Opposing Natural Teeth
}

\author{
Authors \\ Humaira Tanvir ${ }^{1 *}$, Zoya Tanvir $^{2}$, Jasmina Tabeen Bhatt \\ $1_{*}$ Assistant Professor, Department of Prosthodontics, IDST, CCSU, India \\ ${ }^{2}$ Post Graduate student, Department of Pedodontics and Preventive dentistry, IDST, CCSU, India \\ ${ }^{3}$ Post Graduate student, Department of Prosthodontics, IDST, CCSU, India \\ *Corresponding Author
}

Humaira Tanvir

\begin{abstract}
Overdentures have a significant reputation in allowing even hopeless teeth to be retained and used for supporting complete dentures. The combination of a tooth supported as well as a precision attachment retained overdenture has been rarely reported in literature. We present a case of an elderly female patient with an intact maxillary natural dentition and a kennedy class 1 modification 1 partial edentulous situation in the mandible with mandibular anterior present except left canine. Treatment plan included extraction of the mandibular central incisors, intentional endodontic treatment of remaining three mandibular anteriors and mandibular left first premolar. This was followed by the restorative phase of placing a CEKA intra radicular attachment with nylon ring that was incorporated in the metal housing held by the denture. The patient was extremely satisfied with the outcome of the treatment.

Keywords: endodontic, tooth preparation, overdenture, immediate overdenture, precision attachment.
\end{abstract}

\section{Introduction}

While the transition from complete dentulism to complete edentulism takes decades, the effort of preserving natural teeth among various prosthetic treatment options still goes to the concept of overdentures. Even in the present era of implants, the concept of overdenture is the basis for implant supported overdentures. Overdentures supported on natural teeth are of different types, but irrespective of their type they provide significant biological advantages. ${ }^{1}$ The most significant advantage being that it is an established preventive prosthodontic measure that diminishes bone resportion. ${ }^{2,3}$ With the support of natural teeth, it aids in improved masticatory efficiency, psychological well being, directional sensitivity and improved oral sterognosis. $^{4,5}$ Every prosthodontist should incorporate this treatment option in his armory to contribute to the gradual transition from natural dentition to complete denture. A tooth supported overdentures do pose some difficulties, the chief one being they are both tooth and tissue supported prosthesis. In such cases the distribution of stresses between retained abutments and the soft tissues should be free from being concentrated on a particular surface. ${ }^{6}$ Within different types of tooth supported overdentures, the conventional tooth supported overdenture (with or without coping) is more preferred than precision retained overdentures. Attachment retained overdentures although have 
added advantages of facilitating the retention and stability, ${ }^{7,8}$ they are, however technically sensitive due to which even minor errors that are not under the control of the clinician or technician can result in poor or non fitting of the attachments.

This article in the form of a case report presents a case of an elderly female patient whose occlusal rehabilitation posed a challenge since opposing dentition was natural. Clinical procedure associated with the fabrication of precision retained overdenture has been briefly presented.

\section{Case Report}

An elderly female patient in her early fifties reported to the post graduate wing of the department of prosthodontics for replacement of missing posterior mandibular teeth. Patients medical, social, drug and dental history did not signify to have an impact on future dental treatment. With all systemic and local factors within normal limits, the extra oral examination revealed a short upper lip which subsequently resulted in a high lip line, a short and thin maxillary lip compounding to increase visibility of maxillary anterior teeth and a very pronounced mesial attrition of maxillary central incisors that presented a hallmark of her facial feature. Intra oral examination revealed a kennedy class 1 modification 1 partial edentulous arch in the mandible extending from canine on right side and beyond first premolar on left side respectively (Fig 1a). Negative intra oral features included generalized plaque, localized stains, grade III mobile (tooth no 31 and 41), grade I mobile (tooth no 32 and 42), intact maxillary natural dentition, bilaterally attrited mesial surfaces of maxillary central incisors, bucally placed maxillary molars with slight supraeruption of palatal cusps. Positive occlusal features included a functional anterior guidance and left premolars maintenance of vertical dimensions of occlusion (Fig 1b). After a thorough clinical and radiographic examination, the patient was presented with various treatment options that included restoration of distal extension with implant supported crowns, immediate overdenture (tooth supported), a conventional overdenture (tooth

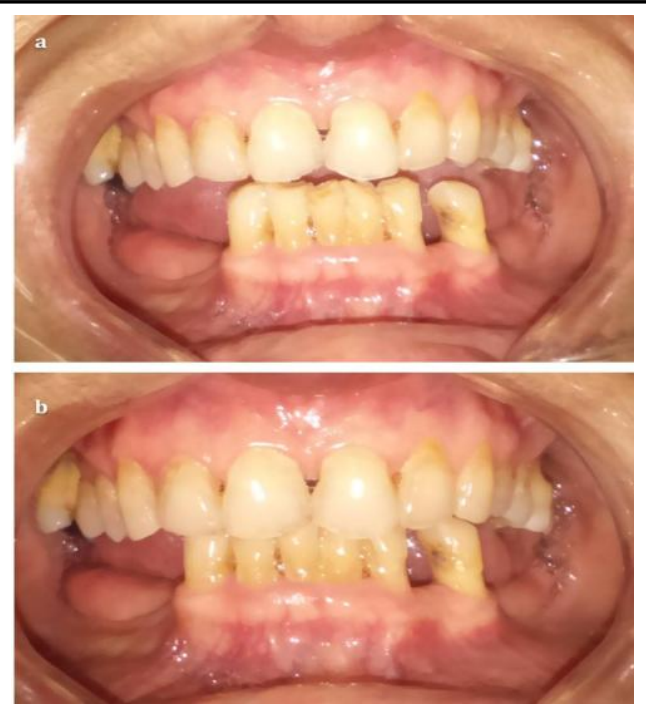

Figure 1: (a) Intra oral view showing freeway space at physiological rest position of the mandible (b) Occlusal vertical dimensions maintained on the left premolar area.

supported or precision attachment retained). After a thorough explanation of each treatment option in terms of procedures, cost efficiency and time taken, the patient consented for the fabrication of precision attachment retained overdenture in the mandibular arch. Preliminary diagnostic impressions were made at two different times using irreversible hydrocolloid (CA 37; Cavex, Haarlem, Holland). The first one was before extraction and the second one after extraction, endodontic treatment and tooth preparations. The treatment had to be divided into phases which included a preparatory phase involving extraction of the mandibular central incisors followed by intentional endodontic treatment of all remaining mandibular anterior teeth including the left first premolar. Restorative phase started with the preparation of all mandibular teeth upto a level of 1 to $2 \mathrm{~mm}$ above the free marginal gingiva (Fig 2a). Final impressions were made using a custom tray, for which a full wax spacer was adapted. The mandibular border molding was done using low fusing impression compound (DPI Pinnacle tracing sticks) and final impression was made in light body addition silicone (Aquasil LV, Dentsply, Caulk, Germany). Master cast was poured in type IV dental stone (Kalrock, Kalabhai). After recording maxillomandibular relation, try in was done and mandibular overdenture was fabricated. 
Preparation of post spaces (tooth no 34 and 43) (Fig 2b) were done that would conform to receive the post of an intra radicular prefabricated attachment (CEKA Preciline, Waregem, Belgium) (Fig 2c).

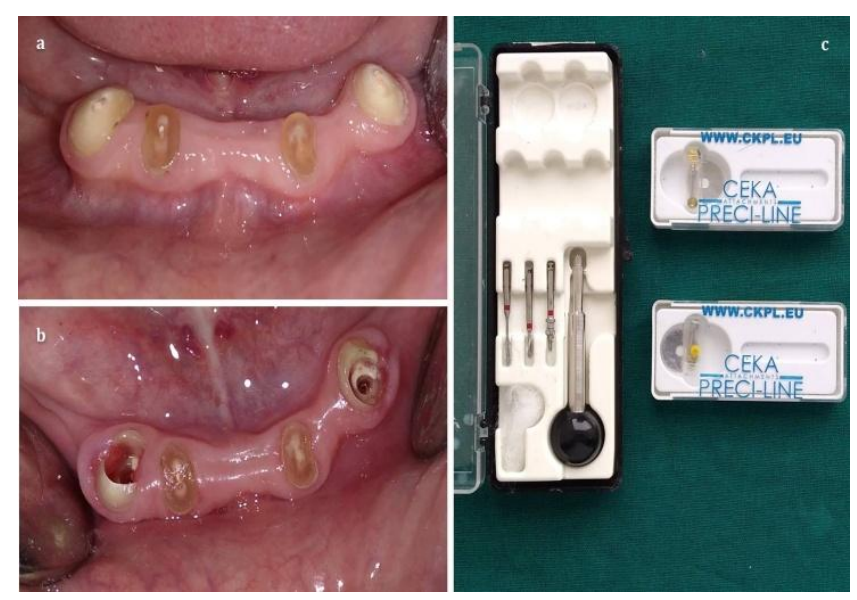

Figure 2: (a) Tooth preparations to provide way for precision attachment (b) Post space prepared for planned teeth (c) CEKA precision attachment kit used for the case.
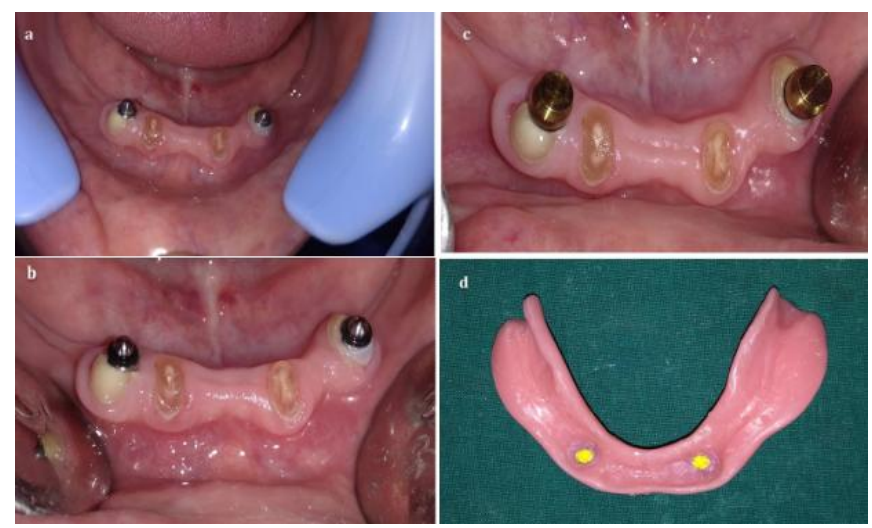

Figure 3: (a) Fitting of precision attachment (b) Blocking undercuts after cementation (c) Fitting of the metal housing (d) Pickup of the metal housing by the denture

After preparation of the post space the respective attachment to selected teeth $(34,43)$ were luted with the dual cure resin cement (Maxcem Elite ${ }^{\mathrm{TM}}$, Kerr, California, US) (Fig 3a) followed by blocking of the undercut with a nylon ring provided with the kit (Fig 3b). Once the nylon ring was in place, a metal housing was attached to the overlying ball end (Fig 3c). A pick up space was created within the permanent mandibular denture which would allow the metal housing to pick up the nylon ring along with it (Fig 3d). In this way the precision attachments were fitted within the natural teeth and the denture. On the day of insertion a clinical remount procedure was undertaken to correct occlusal discrepancies. The mandibular overdenture was delivered to the patient along with a written list of instructions regarding post insertion maintenance. The patient was put on a follow up protocol and during one of her subsequent visits, she expressed her satisfaction with the outcome of the denture (Fig 4).

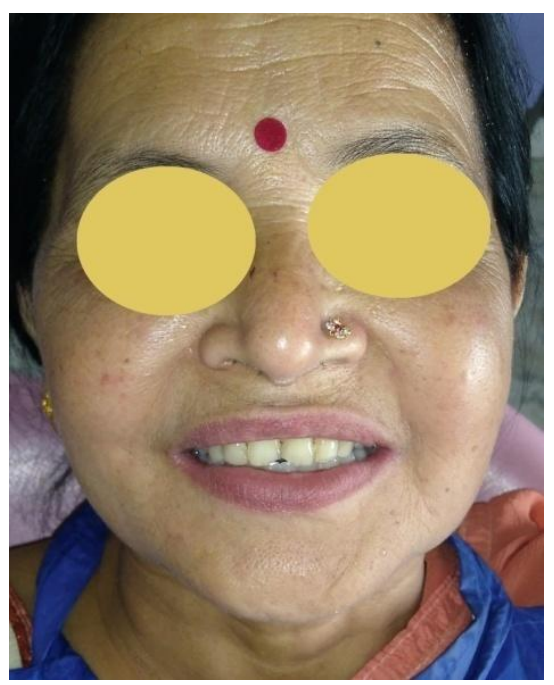

Figure 4: Extra oral view at post insertion follow up

\section{Discussion}

Occlusal rehabilitation of an elderly female patient with maxillary intact natural dentition has been presented in this case. The feature of this case report is that both tooth supported and precision supported overdenture have been done in a single case. While the two lateral incisors on either side of the mandible were used as tooth supports, the left mandibular first premolar and right mandibular canine housed the precision attachments for retention. While the primary purpose of precision attachment is to retain the dentures, certain designs of metal housing allows them to provide support also. ${ }^{8,9}$ The main problems arising from such combination is the probability of even contacting after the dentures have been placed. To overcome such discrepancy, we relined the region of the 
overdenture that was in contact with the natural teeth using a self cure denture base resin. Failure in placing even and simultaneous contacts between the denture and the underlying teeth results in decreased biting force, decreased chewing efficiency, discomfort, trauma to adjacent tissue, stress concentration over one particular tooth and could even lead to fracture of the denture if uneven contacts are present. ${ }^{4}$

The occlusal side is also based on the same principles of even and simultaneous contacts. Establishing a balanced occlusion in centric and eccentric is essential in such specialized cases. ${ }^{10}$ since in this case the opposing teeth were natural dentition, therefore it was important to fit the occlusal surface of the artificial teeth into the worn out occlusal surface of natural teeth. Occlusion should be considered at all levels, including preserving the existing periodontal condition of the abutment teeth. ${ }^{11}$ The periodontal condition of abutments during follow up visits should be good and comparable to earlier status. ${ }^{12}$ Such comparative tooth conditions will indicate the efficiency of overdenture. The ideal procedure for increasing the fit of natural teeth into the artificial teeth is using a functionally generated path. ${ }^{13}$ The concept of gnathodynamic teeth arrangement involves arranging the teeth in occlusion that are essentially biocompatible to the stomatognathic system. ${ }^{14}$ Most of the clinical errors are evident at the time of denture insertion, ${ }^{15}$ therefore a clinical remount procedure is essential to correct occlusal discrepancies that result due to materials or that occur due to not carrying certain procedures. ${ }^{16}$ One problem associated with acrylic teeth is the long term maintenance of balanced contacts which can be overcome by fabricating occlusal surfaces in metal alloy. ${ }^{17}$

\section{Conclusion}

Precision attachment retained overdenture provide a better treatment modality if the patient is properly motivated regarding the maintenance of oral hygiene. The choice of attachment should be based on the pattern of stress distribution from these attachments through the abutments and other structures. An overdenture improves retention, stability, maintains proprioception, prevents residual ridge resorption and improves patient satisfaction.

\section{Acknowledgements}

The authors would like to acknowledge the efforts of the staff of the department of periodontology, oral medicine, endodontics and prosthetic laboratory for their valued contribution towards the completion of this case.

\section{References}

[1] Morrow R, Feldman E, Rudd K and Trovillion H. Tooth supported complete dentures: An approach to preventive prosthodontics. J Prosthet Dent 1969; 21:512.

[2] Mattoo KA, Kapoor A, Jain S. Immediate overdenture - an alternative option in preventive prosthodontics. Med. Res. Chron, 2015; 2: 26-29

[3] Mattoo KA, Yadav L, Rahman SU. Immediate overdenture - a treatment option for bone preservation. J Med Sci Clin Res 2015; 3: 387982.

[4] Rissin L, House J, Manly R and Kapur K. Clinical comparison of masticatory performance and electromyographic activitv of patients with complete dentures, overdentures, and natural teeth. J Prosthet Dent 1978; 39:508.

[5] Singh V, Mattoo KA. Oral Stereognosis pattern in patients with dental prosthesis in the elderly population. Int J Clin Exp Physiol 2014; 1:2115.

[6] Winkler S (1996) Essentials of complete denture prosthodontics, 2nd edn. Ishiyaku Euro America, St. Louis, pp 384-401.

[7] Mattoo KA, Singh M, Singh SP. Precision retained partial denture - A proxy treatment option for full mouth rehabilitation. Med. Res. Chron., 2014;1(2):144-149.

[8] Burns DR, Ward JE. A review of attachments for removable partial denture design: part 2 . Treatment planning and attachment selection. Int J Prosthodont 1990; 3:169-174. 
[9] Burns DR, Ward JE. A review of attachments for removable partial denture design: part 1 classification and selection. Int $\mathrm{J}$ Prosthodont 1990; 3: 98-102.

[10]Mattoo KA, Garg R. Incorporating basic principles of support and balanced occlusion to improve longevity of over denture. Dentistry NX, Dec 2011.

[11]Lauciello FR, Ciancio SG. Overdenture therapy: a longitudinal report. Int $\mathrm{J}$ Perio Rest Dent 1985;5:62-71.

[12]Hussey DL, Linden GJ. The efficacy of overdentures in clinical practice. $\mathrm{Br}$ Dent $\mathrm{J}$ 1986;161:104-7.

[13]Mattoo KA, Sivach A, Jain S. Gnatho dynamic teeth arrangement in complete denture prosthesis. J Med Sci Clin Res 2015; 3: 3875 78.

[14]Brill N. Adaptation and the hybrid prosthesis. J Prosthet Dent 1955; 5: 811- 23.

[15]Zarb, Hobrick, Eckert, Jacob (2012) Prosthodontic treatment for edentulous patients: complete dentures and implant-supported prostheses, 13th edn. Elsevier, St. Louis, pp 290-295.

[16]Winkler S (1996) Essentials of complete denture prosthodontics, 2nd edn. Ishiyaku EuroAmerica, St. Louis, pp 384-401.

[17]Mattoo KA, Mahajan P, Rahman S. A novel technique to fabricate occlusal surfaces for artificial resin teeth in base metal alloys. Int $\mathbf{J}$ Innov Sci Res 2014; 9:167-174. 